Illinois State University

ISU ReD: Research and eData

Theses and Dissertations

3-10-2017

\title{
The effectiveness of a 4-week yoga intervention on the activation and timing of transverse abdominis and lumbar multifidus, pain and functional disability among healthy and low back pain participants
}

Tamara Sagadore

Illinois State University, tsagadore@gmail.com

Follow this and additional works at: https://ir.library.illinoisstate.edu/etd

Part of the Kinesiology Commons

\section{Recommended Citation}

Sagadore, Tamara, "The effectiveness of a 4-week yoga intervention on the activation and timing of transverse abdominis and lumbar multifidus, pain and functional disability among healthy and low back pain participants" (2017). Theses and Dissertations. 708.

https://ir.library.illinoisstate.edu/etd/708

This Thesis is brought to you for free and open access by ISU ReD: Research and eData. It has been accepted for inclusion in Theses and Dissertations by an authorized administrator of ISU ReD: Research and eData. For more information, please contact ISUReD@ilstu.edu. 


\title{
THE EFFECTIVENESS OF A 4-WEEK YOGA INTERVENTION ON THE ACTIVATION
}

\section{AND TIMING OF TRANSVERSE ABDOMINIS AND LUMBAR MULTIFIDUS, PAIN AND FUNCTIONAL DISABILITY AMONG HEALTHY AND LOW BACK PAIN PARTICIPANTS}

\author{
Tamara Sagadore
}

\section{Pages}

Low back pain (LBP) poses a significant long-term health problem and requires the exploration of complementary alternative medicines, such as yoga. LBP patients often present with a delay in the onset of contraction of core musculature, which is necessary to stabilize the spine in dynamic movements. The aim of this study was two-fold. First, it was to determine the effectiveness of a 4-week yoga intervention on the timing of muscle activation and activation ratio of the transversus abdominis (TrA) and lumbar multifidus (LM) muscles among all participants. Second, it was to determine the effectiveness of a 4-week yoga intervention on the visual analogue pain scale (VAS) and functional disability levels as measured by the Oswestry disability index (ODI) among LBP participants. A controlled laboratory study was conducted in healthy participants $(n=10)$ and those with LBP $(n=14)$ between the ages of 18-30. All participants underwent a 30-minute bi-weekly 4-week yoga intervention for LBP taught by a certified yoga teacher. The primary outcome measures were the ODI, VAS, and TrA and LM muscle activation and timing. All outcomes were measured before and after the 4-week intervention. Statistical analyses of the results were performed using $2 \times 2$ analysis of variance for

group comparison of the outcomes measures, and t-tests were used for intra-group comparison of the LBP participants. The pain scores were not significantly different between conditions 
$(\mathrm{p}=.239)$, but there was a strong effect size (0.87). The ODI scores were statistically significant $(p=.049)$ but does not show clinical significance due to the weak effect size and confidence interval that crossed 0 (CI -0.55-0.94). There were no significant differences between the groups for muscle timing or thickness after 4 weeks of yoga for either $\operatorname{TrA}(\mathrm{p}=.101)$ or $\operatorname{LM}(\mathrm{p}=.437)$. A 4-week yoga intervention may provide benefits to participants with and without LBP for decreasing pain and functional disability however a larger and longer duration study may be required to provide more definite evidence.

KEYWORDS: Core muscle performance, Visual analogue pain scale, Oswestry disability index, Ultrasound imaging, Complimentary alternative medicine, Rehabilitation. 
THE EFFECTIVENESS OF A 4-WEEK YOGA INTERVENTION ON THE ACTIVATION AND TIMING OF TRANSVERSE ABDOMINIS AND LUMBAR MULTIFIDUS, PAIN AND FUNCTIONAL DISABILITY AMONG HEALTHY AND LOW BACK PAIN PARTICIPANTS

TAMARA SAGADORE

\author{
A Thesis Submitted in Partial \\ Fulfillment of the Requirements \\ for the Degree of \\ MASTER OF SCIENCE \\ School of Kinesiology and Recreation \\ ILLINOIS STATE UNIVERSITY
}


Copyright 2017 Tamara Sagadore 
THE EFFECTIVENESS OF A 4-WEEK YOGA INTERVENTION ON THE ACTIVATION AND TIMING OF TRANSVERSE ABDOMINIS AND LUMBAR MULTIFIDUS, PAIN AND FUNCTIONAL DISABILITY AMONG HEALTHY AND LOW BACK PAIN PARTICIPANTS

TAMARA SAGADORE

COMMITTEE MEMBERS:

Noelle Selkow, Chair

Rebecca Begalle 


\section{ACKNOWLEDGMENTS}

The authors gratefully acknowledge the participants in the study, Carmen Champion,

RYT, for her assistance in designing and teaching all eight yoga classes and Main Street Yoga in Bloomington, Illinois for allowing the use of the yoga studio space to host the study.

I dedicate this work to my friend Jo, who was a passionate yogi and strived to help others in everything she did.

T.S. 


\section{CONTENTS}

Page

ACKNOWLEDGMENTS

$\begin{array}{ll}\text { CONTENTS } & \text { ii }\end{array}$

TABLES $\quad$ iv

CHAPTER I: IINTRODUCTION 1

CHAPTER II: REVIEW OF THE LITERATURE

$\begin{array}{ll}\text { Anatomy } & 4\end{array}$

Bony $\quad 4$

Joint $\quad 5$

Intervertebral Disks $\quad 6$

Ligament $\quad 6$

$\begin{array}{ll}\text { Musculature } & 7\end{array}$

Low Back Pain $\quad 11$

Risk Factors for Low Back Pain $\quad 13$

The Core - LBP and Effects on Core $\quad 15$

Exercises for the Core 16

$\begin{array}{ll}\text { Yoga } & 17\end{array}$

$\begin{array}{ll}\text { Yoga and Core Strengthening for LBP } & 18\end{array}$

Yoga Interventions for LBP Already Done $\quad 19$

Measurement of the Core by Ultrasound 24

Questionnaires for Pain and Functional Disability 25

$\begin{array}{ll}\text { CHAPTER III: METHODS } & 27\end{array}$

$\begin{array}{ll}\text { Study Design } & 27\end{array}$

$\begin{array}{ll}\text { Participants } & 27\end{array}$

$\begin{array}{ll}\text { Instrumentation } & 28\end{array}$

$\begin{array}{ll}\text { Ultrasound imaging } & 28\end{array}$

Pain - Visual Ultrasound $\quad 28$

Functional Disability - Oswestry Disability Index $\quad 29$

$\begin{array}{ll}\text { Procedures } & 29\end{array}$

Data Reduction $\quad 30$

$\begin{array}{ll}\text { Statistical Analysis } & 31\end{array}$ 
CHAPTER IV: RESULTS

CHAPTER V: DISCUSSIONS

CHAPTER VI: CONCLUSIONS

REFERENCES

APPENDIX: YOGA POSES PERFORMED 


\section{TABLES}

Table

Page

1. Demographics of Participants 28

2. ODI and VAS Scores Following a 4-Week Program Yoga Among LBP Participants 33

3. TrA Activation and Timing Following a 4-Week Yoga Program 33

4. LM Activation and Timing Following a 4-Week Yoga Program 33 


\section{CHAPTER I: INTRODUCTION}

Low back pain (LBP) is one of the most common musculoskeletal health problems in society today and has reached an epidemic level. ${ }^{1,2}$ It is estimated to affect at least $70 \%$ of the general population at some point in their $\operatorname{lives}^{2-4}$ and $5-10 \%$ of American adults will experience chronic LBP. ${ }^{5,6}$ LBP is defined as non-specific pain between the $12^{\text {th }}$ rib and the inferior gluteal folds that can be accompanied by leg pain. ${ }^{1}$ Most cases recover quickly, however some are at risk of becoming chronic cases of pain and disability. ${ }^{2}$ The strain on the health care system from LBP is significant as it is a common reason why individuals seek medical attention. ${ }^{2}$ In addition, if early detection and treatment for LBP is not done, the effects on the individual could be severe as disability may occur ${ }^{7}$ resulting in many consequences, including an inability to work or care for oneself. ${ }^{8}$

A risk factor of LBP is weakness and lack of control of the deep trunk musculature ${ }^{8}$ including the transversus abdominus (TrA) and lumbar multifidus (LM). ${ }^{9}$ The segmental stability of the spine is provided by co-contraction of the LM and TrA to keep the spine in a neutral posture. ${ }^{9}$ In those with LBP, alteration in muscle activity of the $\operatorname{TrA}$ and LM have been observed. $^{9}$

Mobility and stability of the lumbopelvic region can be ensured by the increased segmental stabilization from effective activation of TrA and LM muscles, ${ }^{9}$ which will improve outcomes in individuals with LBP. Segmental stabilization and strengthening exercises effectively reduce pain and functional disability in individuals with LBP compared to a strengthening program alone through increased muscle activation of the $\operatorname{TrA}{ }^{8} \operatorname{TrA}$ thickness increased when performing the following exercises: a side bridge, the abdominal drawing in 
maneuver (ADIM) during a crunch, and the quadruped exercise which involves upper and lower extremity lifts in opposition. ${ }^{10}$

Current research and evidence based guidelines for management of LBP have suggested that exercises for strength and mobility are useful. ${ }^{3}$ Various types of yoga have been used as a treatment method for LBP as an alternative therapy to traditional exercise. ${ }^{11}$ Yoga is currently increasing in popularity as a potential treatment for LBP. ${ }^{12}$ In the United States, more than half of patients with LBP use complimentary treatments and yoga is among the most common complementary treatment used. ${ }^{2}$ Approximately $20 \%$ or 15 million Americans report having practiced yoga at least once exclusively for LBP relief., ${ }^{2,43}$ Yoga is an ancient form of health promotion involving physical activity postures (asana), breathing techniques (pranayama), and relaxation methods and meditation (dyana) to improve mind-body awareness. ${ }^{2,11,14}$ Progressions through posture sequences and meditation in yoga aims to challenge joint flexibility, muscle strength and balance. ${ }^{12}$ Yoga has demonstrated both musculoskeletal and psychological benefits through traditional poses adjusted for those with LBP. ${ }^{11,15,16}$

Activation patterns of five hip and trunk muscles during 11 common yoga poses have been examined and it was concluded that specific core muscle firing depends on trunk and pelvic positions in those poses. ${ }^{17}$ The high plank, low plank and upward facing dog can be used to effectively activate the external oblique, one of the core muscles, however intrinsic musculature was not assessed. $^{17}$

To date, no studies have examined specific spinal stabilizing muscle changes from a yoga intervention for LBP patients. The aim of this study is two-fold. First, to determine the effectiveness of a 4-week yoga intervention on the timing of muscle activation and activation ratio of the TrA and LM among all participants. Second, to determine the effectiveness of a 4- 
week yoga intervention on the visual analogue pain scale (VAS) and functional disability levels as measured by the Oswestry disability index (ODI) among LBP participants. It is hypothesized that both groups of participants in the yoga intervention, regardless of their LBP status, will experience an increase in TrA and LM muscle thickness and faster timing of activation. LBP participants will also improve outcome scores for pain and functional disability. 


\section{CHAPTER II: REVIEW OF THE LITERATURE}

\section{Anatomy}

\section{Bony}

The lumbar spine is comprised of five vertebrae. A vertebra is composed of a body for weight bearing that is the anterior bean shaped part of the bone. The vertebral bodies are broad to support more weight on the spine, the upper body and trunk. The pedicles arise from the posterior aspect of the vertebral body then unite via the lamina. The neural arch or vertebral foramen is formed by the pedicles on either side, the lamina posteriorly and the vertebral body anteriorly. This arch houses the spinal cord in the spinal canal acting to protect it. The transverse processes project laterally from laminae and are long for leverage and thin in cross sectional area in the lumbar spine. The most prominent spinal projection is the spinous process with superior borders projecting posterior. Two sets of articular processes arise from the lamina, a superior facet and an interior facet. ${ }^{18}$

The pelvic girdle is formed by two innominate bones and the sacrum. The innominate bones are a pair of bones comprised of three fused bones: the ilium, the ischium and the pubis. The anterior junction of the pelvis is formed by the pubic symphysis and the posterior junction, the sacroiliac joint, is formed by the articulation of the wedge shaped sacrum for stabilization of the pelvis to the innominate bone, specifically the ilium. ${ }^{18}$

The sacrum is a fused bone consisting of five levels. The sacrum is a broad triangular thick bone that is responsible for stabilizing the pelvis. The sacrum is smooth anteriorly and rougher posterior for muscle and ligament attachment.

The innominate bones have many distinct landmarks. Laterally, the acetabulum, a fossa for the head of the femur, faces interior, anterior and lateral. The superior aspect of the 
acetabulum is made up of the ilium, the interior aspect of the acetabulum is made up of the ischium and the anterior aspect is made up of the pubis. The iliac crest on the most superior aspect of the ilium runs from the anterior superior iliac spine (ASIS) to the posterior superior iliac spine (PSIS). The iliac fossa is formed inferior and anterior to the iliac crest to house and protect viscera and provide muscle attachment for lower extremity hip flexors. Interior to the ASIS, a second smaller bony prominence exist called the anterior inferior iliac spine (AIIS). The pubis portion of the innominate bone is comprised of a superior and inferior pubic ramus. These rami along with the ischium create a passage called the obturator foramen for nerves and vessels to safely pass from the trunk to the lower extremity. The ischium is the most distal bony component of the innominate. The ischial tuberosity is a roughened surface area long the most inferior aspect of the ischium where the hamstring muscle group attaches. The ischial tuberosity continues posterior and superior until the ischial spine protuberance. ${ }^{18}$

\section{Joint}

The superior and inferior articular facets of the vertebrae form the zygapophyseal joints with the vertebra above or below ${ }^{18}$ and are surrounded by a capsule. ${ }^{19}$ These diarthodial joints support $20 \%$ of the body weight. ${ }^{18}$ The concave superior articular process or facet faces medially and posterior to articulate with the convex inferior articular processes or facets which face laterally. ${ }^{19}$ In the lumbar spine the joints are oriented in the sagittal plane which direct primarily flexion and extension movement ${ }^{18}$; however, some side flexion is still permitted. ${ }^{19}$ At levels L13 the facet joints are oriented in the sagittal plant and the facet of L4-L5 are oriented in the frontal plane. ${ }^{18}$ The facet joints provide $40 \%$ of the torsional and shear strength. ${ }^{19}$ 
The pubic symphysis forms the anterior articulation of the two pubic bones of the innominates. It contains a small fibrocartilaginous disk between the pubic bones. This joint allows for compression and distraction, as well as anterior and posterior rotation.

The sacroiliac (SI) joints are made up of the sacrum articulating with iliac portion of the innominate bones. There are two SI joints on either side of the sacrum. The combined synovial and syndesmotic joints are varied in their shape and size. Many concave and convex surfaces make up of the corresponding bones make the SI joints very stable with limited mobility. ${ }^{18}$

\section{Intervertebral Disks}

The disks are composed of the outer annulus fibrosis, a tough dense outer layer and the nucleus pulposus, the inner flexible layer. ${ }^{18}$ The inner layer has a higher water content and is well developed in the lumbar spine. ${ }^{19}$ Intervertebral disks are located between the vertebrae and make up $20-25 \%$ of the total length of the vertebral column. ${ }^{19}$ They have several functions including aiding in increasing range of motion for the spinal column and absorbing compression and rotational shock. ${ }^{18,19}$ Holding the vertebrae together and separating the vertebrae so they can move as segmental units are secondary functions of the disks. ${ }^{19}$ The amount of stress on the disks relates to the position of the body. Sitting causes the most load followed by standing and then lying supine. ${ }^{18}$

\section{Ligament}

The entire spinal column is reinforced by the anterior and posterior longitudinal ligaments running along the length of the spine attaching to the vertebrae and the disks. The anterior longitudinal ligament is thinnest in the lumbar spine. The supraspinous ligament runs along all 
the spinous processes on the posterior aspect. Between each spinous process the interspinous ligament runs to limit flexion and rotation. Ligamentum flavum runs along the posterior aspect of the vertebral canal along all vertebral levels connecting the lamina. This ligament serves to reinforce the facet joints and due to its elastic nature to help the trunk return to neutral from a flexed position. ${ }^{18}$

The inguinal ligament runs from the ASIS to the pubic symphysis to create the superior border of the femoral triangle. Through this passage, soft tissues run anterior from the trunk to the lower extremity. ${ }^{18}$

The SI joint is joined anterior with the ventral SI ligament and posteriorly with the dorsal SI ligament. Theses are also reinforced with interosseous SI ligaments that fill the space anteriorly of the ilium and posterior of the sacrum within the joint. The dorsal SI ligaments have fibers that run transversely joining the ilium to the sacrum superiorly as well as fibers that run vertically joining the distal sacrum to the PSIS. The ventral SI ligaments attach to the anterior aspect of the sacrum to line the pelvic cavity. ${ }^{18}$

The sacrotuberus ligaments and the sacrospinous ligament are two accessory ligaments providing stability to the SI joint. Blending with the inferior fibers of the dorsal SI ligament, the sacrotuberous ligament runs from the ischial tuberosity to the sarum. The sacrospinous ligament indirectly supports the sacrum running from the ischial spine of the sacrum to the coccyx. ${ }^{18}$

\section{Musculature}

Low back or lumbar spine musculature blends into the complex network of muscles along

the spine. The muscles are frequently interwoven with other muscles to provide dynamic support for posture and movement. The muscles can be broken into intrinsic and extrinsic 
groups. Both the intrinsic and extrinsic groups have layers of muscles to increase their support of the trunk. The extrinsic muscles primary function is for respiration and movement of the scapula and the upper extremity; therefore, influencing the spinal column indirectly. The intrinsic muscles are further divided into superficial, intermediate and deep layers. The deep intrinsic muscles of the spine will be the focus of this study. The intrinsic muscles lie close to the spinal column and directly influence motion and stability of the spinal column. ${ }^{18}$

The deep intrinsic layer posteriorly is comprised of muscles collectively know as the transversospinal muscles whose fibers run from one transverse process to the spinous process above them. The muscles in this group include: semispinalis, multifidus, and rotatores muscles. The multifidi are essential in their role to allow for dynamic segmental stabilization of the lumbar spine during lifting and rotation. In patients with low back pain (LBP), the multifidi muscles demonstrate atrophy, weakness and decreased activation rates. The lumbar multifidus originates on the superior aspect of the sacrum and inserts on the spinous process with the primary function being stabilization of the vertebrae and rotation when unilaterally contract. The semispinalis has three segments based on locations, the thoracis, cervicis and capitis. The semispinalis originates on the transverse processes and insert onto the spinous process 5 to 8 segments above the origin. The main function is spinal extension and ipsilateral lateral flexion. The rotatores originate on the transverse processes and insert on the spinous process of the vertebrae immediately above the origin. Overall the rotatores aid with stabilization of the spine, spinal extension and rotation if unilateral contraction occurs. The deep intrinsic layer is innervated by the posterior primary division of the spinal nerves. ${ }^{18}$

The intermediate intrinsic layer posteriorly is comprised of pairs of iliocostalis, longisimus and spinalis, which together make up erector spinae group with a function to be the primary 
mover of the spinal column into extension and eccentrically controls flexion. The group also controls lateral flexion and rotation when contracting unilaterally. The iliocostalis lumborum originates on the posterior aspect of the iliac crest and inserts on the inferior angles of ribs 6-12. The longissimus thoracis originates from the common erector spinae tendon and inserts on the transverse processes of T3-12 and onto ribs 3-12. The spinalis thoracis also originates on the transverse processes and inserts on the spinous processes of the upper thoracic spine. The posterior primary division of the spinal nerves innervates the intermediate intrinsic layer. ${ }^{18}$

The posterior extrinsic muscles that can affect the spinal column are the latissimus dorsi, the levator scapulae, the rhomboid major and minor and the trapezius. The primary function of this group is to connect the upper extremity to the axial skeleton and influence the scapulohumeral motions. ${ }^{18}$

The latissimus dorsi runs from the spinous process of T6-12 and the lumbar vertebrae via the thoracolumbar fascia and along the posterior iliac crest to insert on the humerus on the intertubecular groove. It functions to extend the spine, anteriorly tilt the pelvis and indirectly stabilize the spine via the fascia. The latissimus dorsi is innervated by the thoracdorsal nerve C6-8. The rhomboid major originates at the spinous process of T2-5 and inserts on the vertebral border of the scapula along the lower two thirds. Both the rhomboid major and minor retract, elevate, and downwardly rotate the scapula. The dorsal scapular nerve level C5 innervates the rhomboid major and minor. The rhomboid minor originates at the inferior portion of the ligamentum nuchae and the spinous process of $\mathrm{C} 7$ and $\mathrm{T} 1$ and inserts on the upper one third and superior angle of the vertebral border of the scapula. The trapezius muscle has upper, middle and lower sections. The lower section will be the focus, originating on spinous process of T8-12 
and inserts on the spine of the scapula in the middle. It functions to depress, retract and upwardly rotate the scapula and is innervated by the $11^{\text {th }}$ cranial nerve..$^{18}$

The anterior extrinsic muscles are the rectus abdominus, the internal obliques, the external obliques and the transverse abdominis. Anteriorly, the rectus abdominus is the primary flexor of the spine and influences posture by rotating the pelvis posterior to decrease lumbar lordosis. The rectus abdominis runs from the pubic crest and pubic symphysis to the costocartilages of ribs 5-7 and the xyphoid process of the sternum. The innervation of the rectus abdominus is the ventral rami of $\mathrm{T} 5-12 .^{18}$

On either side of the trunk the internal obliques (IO) and external obliques (EO) are located. When both contract on the same side the trunk laterally flexes to that side. Contraction of one side internal oblique and the opposite side external oblique the trunk will rotate to the side of the internal oblique. If both EO contract then the trunk will move into flexion and there will be a posterior rotation of the pelvis. If both IO contract simultaneously there will be posterior rotation of the pelvis and flexion of the trunk. Both IO and EO aid with depression of the thorax, compression of the viscera and aid with respiration. The anterior fibers of the EO run from ribs 5-8 and insert onto the aponeurosis of the linea alba and the posterior fibers of the EO runs from ribs 9-12 to the ASIS, the corresponding pubic tubercle and iliac crest anteriorly. The internal and external obliques are innervated by the iliohypogastric, ilioinguinal and ventral rami nerves; T1-12 for the EO and T7-12 for the IO. ${ }^{18}$

The transverse abdominis muscle (TrA), which is anterior and lateral, helps with stabilizing the lumbar spine. The TrA stabilizes the spine like a corset and compresses the abdomen. Individuals with LBP have been observed to have a delay in TrA activation indicating this could be a potential cause. Originating on the anterior iliac crest, lateral half of the inguinal 
ligament, the thoracolubar fascia and the cartilages of ribs 6-12 the TrA attaches to the abdominal aponeurosis to the linea alba, xiphoid process and the pubic symphysis. The muscle is innervated by roots $7-12$ of the intercostal, ilihypogastic and ilioinguinal nerves. ${ }^{18}$

The primary muscle group for spinal stability is the core musculature. ${ }^{20}$ The function and attributes are used to divide the muscles into two groups: the deep core muscles and shallow core muscles. ${ }^{20}$ The deep core muscles are used for maintaining local spinal stabilization and include: the transversus abdominis, lumbar multifidus, internal oblique and quadratus lumborum. ${ }^{20}$

Each lumbar vertebrae is attached to the lumbar multifidus. A co-activation mechanism exists between the lumbar multifidus and the transversus abdominis. Precise motor control by theses two interacting muscles are the primary function for spinal stability. ${ }^{21}$

The shallow stabilizing muscles are also called the global stabilizing muscles and include the rectus abdominus, internal and external obliques, erector spinae, quadratus lumborum and the hip muscle group. These muscles connect the pelvis or lower extremity to the ribs which increases spinal control. ${ }^{21}$ Secondary spinal stability is obtained from these muscles because they are able to produce large torques to counter-balance external forces on the spine. ${ }^{21}$

One must also consider muscles distal to pelvis that attach onto it that will influence pelvic position and indirectly the lumbar vertebrae. Anteriorly the quadriceps muscle group and the hip flexor muscle group muscle must be considered. Posteriorly the gluteals and the hamstring muscles must be considered to affect the pelvis and thus the lumbar spine.

\section{Low Back Pain}

Low back pain (LBP) is the most prevalent musculoskeletal condition. ${ }^{12,22}$ LBP is a worldwide problem with a prevalence of $84 \%$ in the general population sometime within their 
life. ${ }^{22,23}$ Greater than $50 \%$ of general population in the United States are affected by LBP. ${ }^{9}$ It has become one of the largest problems for the public health care system in the western world and now is expanding worldwide. ${ }^{24}$ LBP is the leading cause of activity limitation and absence from work. ${ }^{24,25}$ It is the most expensive health care condition for 30-50 year olds. ${ }^{12}$ Non-seekers of medial attention do not vary in frequency or intensity of LBP they experience. Patients with a history of LBP or women are more likely to seek help for their condition. ${ }^{26}$ Perceived disability among these patients has been related to care seeking then pain intensity. Prevalence of chronic low back pain is $15-45 \%$ with $11-12 \%$ of the population being disabled from it, ${ }^{27,28}$ and $10-15 \%$ of the time acute LBP develops into chronic LBP as symptoms are persistent among adults. ${ }^{27,29}$ All age groups are affected; however, adolescents do not experience the same lowered level of quality of life compared to adults. ${ }^{30}$ Acute LBP patients typically recover quickly and only about $10-15 \%$ of those cases develop into chronic LBP. ${ }^{30}$ One of the main characteristics of LBP is recurrence; however, the term recurrent LBP is a term that is not standardized across studies. ${ }^{30}$ Most LBP episodes are not related to serious diseases and therefore it is the clinician's goal to uncover the small percentage of patients with underlying conditions from the majority with nonspecific mechanical LBP. ${ }^{30}$ A systematic review in 2010 by Hoy et al. ${ }^{24}$ uncovered that LBP was high in early adulthood and symptoms tend to recur. It was found that incidence was the most commonly measured over a 1-year period however some studies included did examine recurrence at 6 months, 2, 3 and 5 years. Duration of LBP has been estimated to be between 15 days to 128 days depending on the overall elapsed time since the patients last episode in particular whether it was from less than 3 month to 6 months at the patient's one-year follow-up. Recurrence rates are higher if the patient has experienced LBP previously. Trunk stiffness increases with LBP, which may further contribute to LBP recurrence. Rates of recurrence vary 
from $24-80 \%$ within one year and $70 \%$ within five years. Prevalence varies greatly as well based on location and timing describing the low back pain. Overall the one year prevalence is approximately $37-38 \%$ from the studies evaluated. ${ }^{24}$

There are two groups of core muscles divided into their functions and attributes.

Patients with LBP have displayed a delayed contraction of the TrA suggesting a potential cause of their pain and have also shown atrophy, weakness and decreased activation of the multifidi muscles. ${ }^{18}$

Choi et al. ${ }^{31}$ found in their systematic review that prevention of LBP is most effective using exercise as an intervention compared to other intervention methods including stress management, shoe inserts, insoles, back supports, ergonomics education and reduced lifting programs. $^{31}$

\section{Risk Factors for Low Back Pain}

It has been suggested that LBP causes are multi-faceted in nature. ${ }^{30} \mathrm{~A}$ few major risk factors for developing LBP are decreased lumbar stability, muscular strength and altered motor control. ${ }^{10}$ Weakness and insufficient motor control of the deep core muscles of TrA and LM are also risk factors of LBP. ${ }^{9}$ Trunk musculature ensures mobility and stability of the lumbo-pelvic region during activity so if there are changes to TrA and LM then commonly LBP is seen. ${ }^{21}$ Among the adolescent population, weakness in the abdominals has also been identified as a potential cause. ${ }^{32}$ Selective atrophy of LM after the first episode of LBP was observed to be unlikely to revert and therefore predisposed the individual to further episodes of LBP due to the

lower muscular stability and protection to the spine. ${ }^{33}$ Teyhen at al. ${ }^{34}$ demonstrated increased thickness of the TrA muscle occurred during the ADIM alone or with the quadruped with 
extremity lifting. To increase thickness of both the TrA and the internal oblique (IO) muscles, the side plank and the abdominal crunch should be performed. ${ }^{10}$ Franca et al in 2010 has demonstrated that strengthening segmental stabilizing muscles reduces pain and functional disability among those with chronic LBP. This stabilization also improves activation of the TrA muscle. Therefore, as described above, one important risk factor for those with chronic LBP is weakness and delayed activation of the deep abdominal muscles such as the transversus abdominis (TrA) and the lumbar multifidus (LM) ${ }^{8}$

A common risk factor associated with LBP is age. Studies have found that LBP is highest in ages 30-39 and overall increases with age until age 60 years of age; however, prevalence of LBP is a very common problem among adolescents. ${ }^{24}$ It has been identified that LBP usually begins early on in life with most symptoms between 35-55 years. This is when costs associated with LBP are seen from absenteeism, and symptoms increases with age. ${ }^{27}$ Therefore this warrants investigation into the causes of LBP in the years leading up to age 30 that may help prevent LBP through an intervention. ${ }^{27}$

Women have been observed to have higher prevalence of LBP indicating that gender could be a risk factor for LBP. Women tended to take more time off work as well as being more likely to develop LBP. ${ }^{24}$

Other risk factors for LBP include lifestyle conditions and demographics factors. Obesity and body mass index (BMI) have been linked to an increased prevalence of LBP. ${ }^{24,35}$ A metaanalysis showed that overweight or obese individuals with a BMI $>30$ have higher risk and rates of LBP. ${ }^{24,35}$ A strong association was observed for individuals who are overweight and obese to seek care for their LBP and chronic LBP. ${ }^{35}$ 
It has also been concluded that there is a direct causal link between smoking and LBP as smokers had higher rates, severity, medication usage for LBP and lower functional status than nonsmokers. ${ }^{27}$

For LBP to progress towards a chronic state it has been concluded that risk factors which are psychosocial and occupational in nature are the most influencial. ${ }^{27}$ Psychosocial factors such as stress, anxiety, depression and pain are related to the transition from acute to chronic low back care as well as job satisfaction. ${ }^{24}$

\section{The Core - LBP and Effect on Core}

Mechanical stability of the spinal cord is fundamentally essential for normal function. The spinal stability system consists of three interactive subsystems including the passive spinal column, the active spinal muscles and the neural control unit. The passive subsystem includes the boney structures (vertebrae, facet articulations), discs, ligaments and joint capsules. The active system is composed of the musculoskeletal system including the core muscles and tendons surrounding the spine. The neural subsystem involves force and motion traducers in the ligaments, tendons and muscles. All three subsystems are interdependent. Dysfunction of one subsystem of the spinal system can be caused by problems to any of the subsystems. Initially the

neural control system recognizes these injuries or degenerations and will attempt to compensate with the active system. This will lead to long-term consequences including chronic dysfunction and pain. A deterioration of the active subsystem will affect the ability to receive and process neural signals for feedback of muscle tension to the neural system. If adequate muscle tension can't be produced, the deformation may cause injury and the spinal stabilizing system may be compromised in a capacity to be compensatory and adapt and withstand external loads. 
Adaptation and enhancement for the active system can be achieved by training to increase muscle tone, which will decrease the risk of LBP. This can be explained by increased stability to the spinal system to be able to generate more muscle tension. ${ }^{36}$

The nervous system responds to a variety of sensations by the active and passive systems through use of motor control coordination. Overall the central nervous system governs the physical actions of the body and therefore prevents interference for maintenance of spinal stability and lumbar spinal movement. ${ }^{36}$

TrA offers spinal stabilization and protection, however in patients with LBP it plays a role in lumbar spine dysfunction. A delay in the onset of contraction of core musculature has been observed in LBP patients. TrA has also shown the most delay compared to IO and EO in the difference in onset of activation. If TrA plays a role in spinal stability, the delayed activation of the muscle would decrease spinal stiffness at the time of movement. The contraction was also ineffective in controlling reactive forces and thus increasing the risk on the spine for further injury. ${ }^{37}$

\section{Exercises for the Core}

The most effective management strategies of LBP vary widely and inconclusive. These strategies vary most often due to the multi-factoral causes of LBP. Exercise therapy is a commonly used intervention for managing LBP and can vary in design and methods. Individualized stretching and strengthening improved LBP among sufferers. ${ }^{7}$ The abdominal draw-in maneuver that occurs during focused contraction of the deep muscles of the core provides spinal stability and supports the spine in a neutral position. ${ }^{38}$ 
Complimentary and alternative medicines (CAM), such as yoga, have also been used for patients with LBP. Yoga intervention studies for low back pain have shown a decrease in pain and improved back function leading to improved functional abilities. ${ }^{7}$

There have been four types of core strength training identified: motor control, stabilization, segmental stabilization and trunk balance exercises. Due to similarities in principles stabilization, segmental stabilization and motor control exercises all retrain the deep core musculature; ${ }^{9}$ however segmental stabilization exercises increase vertebral stability by targeting the intrinsic musculature of the TrA and LM. ${ }^{8}$

\section{Yoga}

Over two thousand years ago around $3^{\text {rd }}$ century AD yoga arose in India as a holistic exercise system that incorporated spiritual, moral and physical aspects. The purpose of yoga practice as translated from Sanskrit means to achieve spiritual self-realization. Yoga began to become popular in the United States in the 1960s. It first became popular to celebrities and was marketed to pregnant women, seniors and those with low back pain. ${ }^{39}$ Yoga is a complimentary alternative medicine (CAM) form that is used by an estimated 15 million in their lifetime within the United States. Of those participants in yoga, approximately $21 \%$ have used yoga specifically for their back pain. ${ }^{39}$ It is one of the most popular interventions incorporating both the mind and the body and has been validated to aid in levels of pain and functional disability for chronic LBP. ${ }^{1}$ Yoga, as practiced in Western culture, comprises of physical exercise (asana), breathing (pranayama), meditation and relaxation (dyana) $)^{2,40}$ with the aim to create emotional, physical and

inner balance. ${ }^{11,13}$ Progression through the sequence and the meditation component challenges muscular strength, flexibility and balance. ${ }^{3}$ The most commonly used forms of yoga to treat LBP 
are Viniyoga, Hatha yoga, Iyengar yoga and Integrated yoga. ${ }^{1}$ Different schools of yoga vary the proportions of physical practice, breathing and mental activity throughout their practices. Most studies using varying forms of yoga found positive benefits on LBP. ${ }^{41}$

There are limited adverse affects to participating in yoga; however, some studies have reported adverse effects such as vertebrobasilar artery occlusion, orbital varices and muscle strains but these are rare and infrequent. ${ }^{39}$ The practice of yoga is most common among baby boomers, women, city dwellers and those with higher education and is used most frequently as additional treatment for depression, anxiety and neck/back pain. ${ }^{39}$ The benefits of yoga are greater than just physical exercise as yoga combines physical exercise and focus, along with education on posture, self-care and becoming more self-aware in a relaxed state. ${ }^{42}$ There are long term benefits to yoga compared to other traditional treatment methods of LBP such as manipulation or exercise therapy as the participants in yoga are encouraged to continue to practice at home after the sessions are complete. ${ }^{3}$

Comparing yoga research and identifying which yoga methods are used and which low back pain patients benefited from the yoga is difficult because the definition and methods of yoga varied. ${ }^{13}$

\section{Yoga and Core Strengthening for LBP}

From a review of the literature there seems to be very little quantitative data to validate yoga improving core musculature. Ni et al. ${ }^{17}$ examined trunk and hip muscle activation during 11 yoga poses. It was uncovered that the high plank, low plank and upward facing dog poses are effective at activating the external oblique muscle. Other poses were seen to develop the gluteus maximus and longissimus thoracis muscles. Ni et al. ${ }^{17}$ have quantified data on external muscles 
during various yoga poses, however more research is warranted to examine deeper trunk muscles. It was recommended to study the core among healthy participants with LBP as well as individuals without any yoga experience. ${ }^{17}$

Yoga increased strength and stabilization of the spine through physical practice that are required for spinal support. ${ }^{43}$

Patil et al. formulated an integrated yoga therapy module of 20 essential yoga aspects including yoga, breathing and mediation that 30 yoga-panel experts rated as essential for the treatment of LBP. The model was then validated when a study was conducted with a sample of low back pain participants that significantly improved pain, disability and perceived stress. Poses that were deemed as essential include: folded leg lumbar stretch, crossed leg lumbar stretch, bridge pose, lumbar stretch, serpent pose, locust pose, straight leg raise pose, lateral arc pose and half wheel pose. ${ }^{41}$

\section{Yoga Interventions for LBP Already Done}

Yoga has been shown to be more effective at preventing LBP than exercise therapy and self-care. ${ }^{7}$ As such, people who practice yoga are less likely to require further treatment in the future thus reducing the burden on the health care system.

Galantino et al. ${ }^{12}$ used a short 6-week hatha yoga intervention on adults 30-65 years with chronic LBP, which proved to be effective even with a small sample of 21 participants. This warrants further investigation into effects of short-term yoga interventions. Disability was not examined in this study and was identified as an area to explore in future studies. ${ }^{12}$

Williams et al. ${ }^{4}$ have specifically examined the effects of Iyengar yoga for chronic low back pain found a significant reduction in pain, functional disability and pain mediation usage in 
the yoga intervention group compared to a back education group indicating that improvements can be seen in patient outcomes from Iyengar yoga. ${ }^{4}$

Similar to Williams et al. ${ }^{4}$, Sherman et al. ${ }^{44}$ found in their randomized controlled trial that the yoga intervention group had reduced pain, amount of pain medication use and the severity of any disability at week 8 compared to the back exercise group. Both Williams et al. ${ }^{4}$ and Sherman et al. ${ }^{44}$ studies demonstrated that the effects from yoga on pain and disability lasted longer than the groups that used exercises or back education.

Aboagye et al. $^{7}$ compared a medical yoga intervention for treating LBP to exercise therapy by a physical therapist and self-care advice and found that the benefits of early intervention with yoga significantly outweighs the benefits in cost to the individual, employer, and to society overall. The treatment of choice for optimal use of resources is yoga for health improvements as measured by the health-rated quality of life (HRQL). This study focused on the economic support needed for individuals with LBP and based on the results if constrained by resources, medical yoga is the recommended treatment choice. ${ }^{7}$

Saper et $\mathrm{al}^{45}$ utilized LBP participants aged 18-64 who were randomized to a control waitlist group or a once weekly 12-week hatha yoga intervention of 75 minute class length. Classes included breathing and posture and poses were modified to the abilities of each individual. A home yoga practice was facilitated with necessary supplies. The primary outcomes measured were average pain level for the previous week using 0-10 scale, the RolandMorris disability scale and secondary outcomes were a 7-point likert scale on global improvement, health-related quality of life using SF-36 and use of pain medication. Measures were taken at week 6,12, and 26. Overall yoga was found to be more effective at reducing pain and medication use in the short term. ${ }^{45}$ 
In India Tekur et al ${ }^{46}$ conducted a large sample $(\mathrm{n}=80)$ one-week intensive yoga program for chronic LBP patients compared to the control group of physical therapist supervised exercises with lifestyle education and utilized the ODI and spinal flexibility as measured by a goniometer pre and post intervention. The yoga intervention used was an integrated approach to yoga therapy (IAYT) for back pain with a holistic approach including physical, mental, emotional, intellectual components. It was found that ODI scores reduced significantly in the yoga group and the yoga group improved more significantly in spinal range of motion in flexion, extension and bilateral lateral flexion. ${ }^{46}$

Williams et al. ${ }^{11}$ compared a control group of standard care to an intervention group participating in 24 weeks of 90-minute session of Iyengar yoga biweekly through the ODI, the VAS, the Beck depression inventory and a pain medication-usage questionnaire. It was found that yoga improved functional disability, pain intensity and depression in LBP participants. Pain-medication usage was also lowered in the yoga group compared to the control group. Follow ups were conducted at 6 months post intervention that found that reductions in disability, pain intensity and depression were maintained from yoga.

Tilbrook et al. ${ }^{42}$ conducted a large $(n=313)$ study comparing yoga to usual care among LBP participants. The yoga group received one-weekly 75 minute yoga classes for 12 weeks progressing each week while the control group only received a booklet on back pain education. Participants were encouraged to use the $\mathrm{CD}$ at least twice a week but ideally practice daily for 30mins. The outcomes measures were the RMDQ, a pain self-efficacy scale and general health measures at baseline, 3, 6 at 12 months from the onset of the study. Greater improvements in back function was observed in the yoga group compared to the usual care group. ${ }^{42}$ 
Cramer et al. ${ }^{2}$ conducted a systematic review and meta-analysis on the effectiveness of yoga for low back pain on eight studies ${ }^{3,12}$. It was found that there is strong short-term effectiveness and moderate long-term effectiveness among valuable outcome measurements for yoga for patients with chronic LBP. Yoga was found to be more effective than education on LBP treatment. Studies examining the effectiveness of yoga on LBP require more vigorous methodology and reporting. Further research should focus on comparing various styles of yoga and evaluating which components of yoga such as the physical postures, breathing or meditation to bring light to the way in which yoga aids in LBP treatment. ${ }^{2}$

Posadki and Ernst ${ }^{1}$ published a systematic review of seven randomized clinical trials $^{3,4,11,12,44-46}$ found that there is evidence that yoga alleviates chronic LBP and that future studies should ensure adequate sample size, use validated outcomes and more control throughout their methods for easy replication and less validity threats. Studies varied between one week to 24 weeks conducting 8 to 24 classes in Hatha, Viniyoga, Iyengar, or non-specified yoga. Control groups did usual care, conventional exercise or usual care with written advice or educational advice. Outcomes examined used the RMDQ, ODI, VAS, Beck depression index, pain medication usage, measured spine flexibility via goineometry, forward reach test and the sit and reach test. Five of the studies showed significant reductions in their outcome measures compared to the control in favor of the yoga intervention. ${ }^{1}$

The systematic review by Hill ${ }^{47}$ found that three of the four randomized control trials (RCT) found yoga to be an effective method to manage LBP and all four studies found that yoga is effective to improve back function. The reviewed studies ${ }^{11,42,46,48}$ compared yoga to various other rehabilitation methods including physical therapy stretches or usual or standard care. There was strong evidence for short-term effects on pain and back disability compared to 
controls and there were moderate long-term effects for reduction of pain and back specific disability. Quality of life improvements where no observed in the short-term or long-term follow up. Limitations of the review found that type of yoga and frequency and length of program varied between studies.

The meta-analysis by Holtman ${ }^{49}$ found similar results to $\mathrm{Hill}^{47}$ through the review of eight $\mathrm{RCTs}^{4,11,12,42,44-46,48}$ and is the most updated review including the two largest RCTs $\mathrm{s}^{42,48}$ conducted. The findings support yoga on short-term improvements in functional disability among patients with chronic LBP and a moderate post-treatment effect. Due to the variability in the types of yoga used in the RCT (Hatha, Iyengar, Viniyoga), the overall focus on strength, flexibility, breathing and awareness focus could be more useful than the type or sequence of yoga used in the varying styles. Overall results confirm use of yoga as treatment for LBP patients who do not see improvements with self-care. Future research should focus on the mechanism of action of yoga on the treatment effects of yoga and compare to other active treatment methods.

The 8 -week pilot study by Hartfiel ${ }^{14}$ on yoga in the workplace suggests that participants perceived less back pain, more serenity and self-assuredness. The use of yoga in the work-place may improve levels of absence, perceived stress and emotional wellbeing. ${ }^{14}$

A review was conducted on the components of yoga interventions by Ward et al. ${ }^{50}$ that described the homogeneity and heterogeneity that exists in treatment of musculoskeletal injuries through yoga. Overall it was found that interventions ranged from 1 week to 24 weeks, and weekly dosage ranged from 1 to 56 hours. For LBP the most common was 12 weeks for the intervention and a once weekly dose of $75 \mathrm{mins}$ during a single class. Frequency of classes ranged from one to six days per week. Most studies conducted classes once per week. Style of 
yoga varied based on the location of the study. The predominant was Iyengar due to its standardization of teacher qualifications and therapeutic protocols, however a generic form of Hatha yoga for LBP patients was also commonly used. Hatha was chosen due to its gentle physical practice for new participants with limited or no yoga experience. ${ }^{50}$

\section{Measurement of the Core by Ultrasound}

Ultrasound (US) imaging is a reliable non-invasive method to measure muscle thickness. It has proven to be reliable and offers strong construct validity to the ADIM for activation of the TrA muscle. The muscle activation is viewed by the changes in muscle thickness. Ultrasound has proven to be as effective as traditional imaging techniques such as MRI, manual muscle testing and electromyography (EMG). Ultrasound offers advantages over other techniques because it allows for less overlap of surrounding muscles. ${ }^{51}$ Objective evaluations are needed for determining the extent to which core strength training can minimize LBP. Quantitative objective measures by US can facilitate identification of statistical differences between experimental and control groups with LBP. ${ }^{8,9}$

Franca et al ${ }^{8}$ used ultrasonography to measure the thickness of TrA and LM boundaries and found that there was a statistical difference between the experimental and the control group which is different then the VAS pain scores that reported no difference between the groups. The scores on the VAS may not have been significant due to the pre and post test scores being low but a reduction in pain was still indicated within the LBP participants to improve their functional disability. ${ }^{8}$ Ultrasound images aid to quantify the morphological changes in the muscle, thickness changes, and the values can define the level of muscle of activation. ${ }^{37}$ 
Images of TrA will be recorded in B mode with the transducer superior to the iliac crest on the right side of the pelvis in the transverse plane along the mid-axillary line. Placing the transducer head on the hyperechoic interface between the TrA to ensure the thoracolumbar fascia was the right most structure enforced standardization. The best images of the abdominal muscles can be captured when the angle of the transducer can be altered. Consistently the transducer can be placed over the lateral aspect of the abdomen so the TrA will be on the right side of the screen. The scale of one centimeter was placed on the right side of the image. Resting and contracted image were examined for TrA and LM thickness measuring the distance between the superior edge $f$ the hyperechoic fascial line to the inferior edge of the superior fascial line. The activation ratios can be calculated by dividing the contracted thickness by the resting thicknes. ${ }^{52}$

TrA activation ratio has been suggested to be an indicator of the ability of the local musculature to stabilize the spine. The ratio compares the contracted state of the muscle to the rested state, which is a measure of strength normalized to the body weight of the individual. Changes in thickness can be representative of increased muscle activation. ${ }^{52}$

\section{Questionnaires for Pain and Functional Disability}

The Oswestry Disability Index (ODI) is an outcome measure to determine a patient's disability and helps the clinician measure the amount of quantitative change over time in their scores and thus their abilities. ${ }^{53}$ The ODI is a commonly used outcome measure for LBP as it can be self-administered and takes little time to complete. The ODI was assessed for reliability and validity proved it to be a tool that can measure disability accurately among a LBP population. ${ }^{54}$ This outcome measure is best suited for a busy environment due to simplicity to administer, score and give quantitative way to monitor treatment effectiveness. ${ }^{54}$ 
The visual analogue scale (VAS) is a simple tool for the majority of patients to use to get a measure of pain. Each scale represents pain intensity and can have descriptors at different points along the continuum. Found to be valid and reliable in a study of knee pain, the VAS provides magnitude of pain. ${ }^{55}$ The VAS is a commonly used assessment instrument for pain in rehabilitation. ${ }^{56}$ The single-item assessment of the VAS utilized for pain but not for disability, because it is proven to be invalid for self-reported disability, and therefore the other instruments must be used such as the ODI. The VAS for disability tested only to be reliable at a good to moderate level, which is lower then the VAS for pain. This may be explained by the fact the word pain is more clear to patients than disability. ${ }^{57}$ 


\section{CHAPTER III: METHODS}

\section{Study Design}

The design of this study was a controlled laboratory study. The independent variables were time of measurements being taken (pre and post) and group (participants having low back pain (LBP) or being healthy (free of LBP)). The dependent variables were VAS and ODI scores, and TrA and LM timing of activation and thickness measured with diagnostic ultrasound. This study was approved by the Institutional Review Board at Illinois State University.

\section{Participants}

Twenty-five participants volunteered to be in the study, 9 males and 15 females. Demographics are presented in Table 1 . Exclusion criteria was $<18$ years of age and $>30$ years of age at the start of the study, have performed yoga in the last year, new LBP treatments started 30 days prior to the intervention, sustained any injury to the body in the last six weeks, could not use stairs and/or get up from the floor unaided, pregnant, have a history of spinal surgery or abdominal surgery, have serious spinal abnormalities (radiculopathy, nerve root compression, spondylosis, spondylolisthesis, tumor, spinal infection, kyphosis or widespread neurological disorder), have had a chronic systemic or connective tissue disease, have a balance disorder, score $>40 \%$ on ODI, or have a shoulder or knee pathology. Inclusion criteria for the low back pain group include the following: having 3 or more episodes of LBP in the past year that resulted in limited activities of daily living (ADL) or more then five times in their lifetime, have an ODI score between $2-40 \%$, be English speaking, have back pain for less than six weeks during an episode, have a mean pain intensity equal to or greater than $1 / 10$ at the time of testing. Healthy 
participants could not have had any injury to the body in the past 6 weeks, including no history of LBP, and an ODI score could not be higher than $0 \%$.

Table 1. Demographics of Participants

\begin{tabular}{lllll}
\hline & Gender $(\mathrm{M} / \mathrm{F})$ & Age (years) & Height $(\mathrm{cm})$ & Weight $(\mathrm{kg})$ \\
\hline Healthy $(\mathrm{n}=10)$ & $(\mathrm{M}=3 / \mathrm{F}=7)$ & $22 \pm 4.24$ years & $170.4 \pm 17.89 \mathrm{~cm}$ & $66.9 \pm 23.09 \mathrm{~kg}$ \\
& & & & \\
\hline LBP $(\mathrm{n}=14)$ & $(\mathrm{M}=6 / \mathrm{F}=8)$ & $23.5 \pm 7.78$ years & $173.1 \pm 23.35 \mathrm{~cm}$ & $93.1 \pm 30.79 \mathrm{~kg}$ \\
& & & & \\
\hline (mean $\pm \mathrm{SD})$ & & &
\end{tabular}

\section{Instrumentations}

\section{Ultrasound imaging}

Ultrasound imaging was obtained using a Terason t3000 M-series portable ultrasound system (Teratech, Burlington, MA) with an $8-15 \mathrm{MHz}$ linear array. It was used to measure TrA and LM muscle activation and onset of the muscle contraction. Intra-rater reliability was established prior to data collection $(\mathrm{ICC}=.97)$.

\section{Pain - Visual Analogue Scale}

The VAS consists of a $100 \mathrm{~mm}$ line, where the scale ranges from left being no pain to right being unbearable pain. The participant places a vertical line to indicate his or her current level of pain. This distance from the left mark was measured in millimeters and recorded. Higher values indicate more pain. Reliability and validity of the VAS has been established for pain intensity in rehabilitation. ${ }^{56}$ 


\section{Functional Disability - Oswestry Disability Index}

The ODI version 2.0 was used to assess the impact of LBP on daily activities. The score was calculated by adding the values of the individual questions to categorize the disability. Categories are broken down as zero to mild disability (0-20\%), moderate disability (21-40\%), severe disability (41-60\%), incapacity (61-80\%) and restricted to bed (81-100\%). ${ }^{53}$ This outcome measure has been recommended to detect meaningful changes in disability status in ADL. ${ }^{54}$ The ODI allows investigation of many domains of an individual's life and can be used for individuals with any scale of LBP from mild to severe. It has been proven as a valid and reliable measure for LBP patients. $^{53}$

\section{Procedures}

Participants arrived for testing wearing comfortable athletic clothing of their choice. Anthropometric measurements of height and mass were recorded as well as a demographic survey to collect age and sex. All participants completed the ODI, to ensure the healthy participants had a score of zero and to take baseline measures for the LBP group. VAS measurements were completed for the LBP group.

The abdominal drawing-in maneuver (ADIM) was taught to all participants prior to ultrasound imaging. The ADIM was used to measure core muscle thickness by ultrasound imaging. The participant was instructed to lie supine with knees flexed to $90^{\circ}$ in the hook lying position for measures of the TrA and in the prone lying position for the LM measurement. This position was the starting and resting position. The participant was instructed to "breath in and then out and draw your belly button to your spine" to perform the contracted position. ${ }^{34}$ Six ultrasound images were taken of TrA and LM each, three at resting and three contracted images. Resting muscle images was taken prior to contracted images. Participants were allowed to 
practice the ADIM three times with clinician feedback on proper form before imaging was collected. ${ }^{34}$ A 10 second movie clip was also recorded during active glenohumeral flexion to 180 degrees to assess when the muscles "turned on" or initiated activation.

The intervention lasted 4 weeks with participants required to attend two yoga sessions per week. Each session lasted 30 minutes with 10 minutes of breathing, mediation, relaxation, stretching, and 20 minutes of yoga pose exercise. Questionnaires were distributed at the end of each session asking participants to subjectively describe how they were feeling, rate their muscle soreness and LBP levels on a scale from 0-10.

The yoga instructor was certified by the Yoga Alliance and had experience instructing individuals with LBP. The yoga style taught was Hatha yoga. The yoga poses were demonstrated and modified to the abilities of each individual to prevent injury (Appendix A). The instructor provided verbal feedback to the participants to assist them in achieving the postures with proper alignment, mechanics and breathing. The yoga series taught emphasized core activation and allowed participants to modify each pose as needed. A large emphasis was placed on using props for support and assistance in postures as needed. Twenty-four to ninety-six hours after the conclusion of the yoga intervention, participants reported to the athletic training facility for ultrasound imaging and completion of the ODI and VAS scores. The primary investigator who performed ultrasound imaging was not told of the participants' LBP status.

\section{Data Reduction}

A second investigator calculated the TrA and LM activation ratio by dividing the contracted muscle thickness by the resting muscle thickness. Use of the activation ratio 
standardizes the activation observed to the resting level and allows for comparison across participants. $^{58}$

The timing of activation was calculated by dividing the number of image frames that were collected over the 10 -second interval. The frame where the TrA or LM started to contract was multiplied by the number of seconds each frame was collected at. This was the reported time that the muscle started contracting. The ultrasound software was used to convert the time of that frame into seconds. ${ }^{58}$ The images were coded so that they did not indicate LBP status.

\section{Statistical Analysis}

Statistical analysis was performed using SPSS (IBM SPSS Statistics for Windows, version 21.0; IBM Corp, Armonk, NY). Separate $2 \times 2$ analysis of variances (ANOVA) were applied to compare muscle activation ratios and timing of activation between the healthy and LBP patients. Paired samples t-tests where used to assess differences in VAS and ODI scores between the LBP group. Alpha was set a priori at 0.05 . Effect sizes were calculated by Cohen's $\mathrm{d}$ to be interpreted for meaningfulness and clinical significance. 


\section{CHAPTER IV: RESULTS}

There were no significant differences between groups for $\operatorname{TrA}(\mathrm{p}>.101)$ and $\operatorname{LM}(\mathrm{p}>.437)$ timing and activation after 4 weeks of yoga. ODI was significantly different $(\mathrm{p}=.049)$, but the effect size confidence interval crossed zero (CI -0.55-0.94). VAS was not significantly different $(\mathrm{p}=.239)$, but the effect size was strong (CI 0.11-1.63). Results are presented in Tables 2-4.

Table 2. ODI and VAS Scores Following a 4-week Yoga Program Among LBP Participants

\begin{tabular}{lllllll}
\hline & ODI & ODI & Effect Size & VAS & VAS & Effect Size \\
& Baseline $t$ & Post-Int. $\dot{t}$ & & Baseline & Post-Int. & \\
\hline LBP & $6.0 \pm 3.8 \%$ & $5.2 \pm 4.1 \%$ & $0.2($ weak $)$ & $13.0 \pm 12.7$ & $6.4 \pm 7.6$ & 0.87 (strong) \\
$(\mathrm{n}=14)$ & & & (CI -0.55-0.94) & mm & mm & (CI 0.11-1.63) \\
\hline
\end{tabular}

Abbreviations: LBP, low back pain; ODI, Oswestry Disability Index; VAS, Visual Analogue Pain Scale (mean $\pm \mathrm{SD})$ $\dagger$ ODI Pre-post significant difference ( $\mathrm{p}=.049)$.

VAS Pre-post difference $(\mathrm{p}=.239)$.

Table 3. Transverse Abdominis Activation and Timing Following a 4-week Yoga Program

$\begin{array}{cccc}\text { TrA Activation } & \text { TrA Activation } & \text { TrA Timing } & \text { TrA Timing } \\ \text { Baseline } & \text { Post-Int. } & \text { Baseline } & \text { Post-Int }\end{array}$

\begin{tabular}{lllll}
\hline Healthy $(\mathrm{n}=10)$ & $1.63 \pm .28$ & $1.45 \pm .25$ & $2.17 \pm .41 \mathrm{~s}$ & $2.05 \pm .42 \mathrm{~s}$ \\
\hline LBP $(\mathrm{n}=14)$ & $1.80 \pm .58$ & $1.73 \pm .47$ & $2.25 \pm .63 \mathrm{~s}$ & $2.20 \pm .52 \mathrm{~s}$ \\
\hline
\end{tabular}

Table 4. Lumbar Multifidus Activation and Timing Following a 4-week Yoga Program

\begin{tabular}{lcccc}
\hline & $\begin{array}{c}\text { LM Activation } \\
\text { Baseline }\end{array}$ & $\begin{array}{c}\text { LM Activation } \\
\text { Post-Int. }\end{array}$ & $\begin{array}{c}\text { LM Timing } \\
\text { Baseline }\end{array}$ & $\begin{array}{c}\text { LM Timing } \\
\text { Post-Int. }\end{array}$ \\
\hline Healthy $(\mathrm{n}=10)$ & $1.08 \pm .11$ & $1.05 \pm .03$ & $2.11 \pm .32 \mathrm{~s}$ & $2.21 \pm .30 \mathrm{~s}$ \\
\hline LBP $(\mathrm{n}=14)$ & $1.08 \pm .09$ & $1.07 \pm .05$ & $2.09 \pm .52 \mathrm{~s}$ & $2.26 \pm .28 \mathrm{~s}$ \\
\hline
\end{tabular}

Abbreviations: TrA, Transversus Abdominis; LM, Lumbar Multifidus

Activation (mean $\pm \mathrm{SD}$ ) is the ratio of the muscle thickness change from a resting to a contracted position during the abdominal draw in maneuver and calculated as a contracted state/resting rate ratio

Timing was calculated as the point when the muscle began to contract when the arm was brought overhead after a three second wait period. 


\section{CHAPTER V: DISCUSSION}

This controlled laboratory study was conducted to evaluate the effectiveness of a 4-week yoga intervention on core musculature, pain and functional disability among healthy and LBP participants. In particular, we were interested in determining if and how yoga may be effective at improving LBP outcomes. The results found that participants with LBP experienced pain relief, but there was no changes found with functional disability, muscle activation and muscle timing. No serious adverse events were reported from the yoga sessions from any of the participants.

While the difference in ODI scores were significant, the effect size confidence interval crossed zero, and as such the change may not be meaningful. The average baseline ODI scores were less than $10 \%$, indicating a population with minor disability. The minimal detectable

change has been reported as $15-16 \% .^{59,60}$ Since the average ODI scores at baseline were less than $10 \%$ and are below the minimal detectable change, this indicates that a change in the scores would not cause a significant difference in a clinical setting. A floor effect may have resulted, where there was not much room for improvement in scores.

Pain on the other hand, showed a strong effect size. Pain decreased by about half in our LBP participants. However, this should be taken with caution. The average baseline VAS scores were below $20 \mathrm{~mm}$ ( 2 out of 10 ). Our population was not in considerable pain during the study and may not be generalizable to a more painful population.

Core muscle ultrasound imaging of the TrA and LM showed no significant changes over the 4-week intervention. Neural changes may have occurred causing an increase in muscle fiber recruitment. Short-term strength training increases the output of motor neurons to the targeted muscles of the training. ${ }^{62}$ The neural transmission is altered by strength training through motor 
neurons controlling the muscles therefore facilitating undetectable strength changes. ${ }^{61}$ Before force generation or muscle thickness is observed there needs to be more efficacy of the motor neural junctions (synapses) and more excitability of the motor neurons ${ }^{62}$ which may have occurred in our study. More time may have been needed for the body to adapt to the neural changes and increase muscle thickness.

Adherence to the yoga intervention was excellent at $96 \%$ with all but one participant completing the minimum of 7 of the 8 classes conducted ( $68 \%$ completed all 8 sessions). The high attendance rate to each of the eight sessions may be attributed to the sense of community that was developed over the 4 weeks among participants. Slade et al. ${ }^{63}$ demonstrated that individuals are more likely to engage in exercise programs and activity that consider their fitness levels, health status and exercise experience. ${ }^{63}$ The yoga classes in this study were beginner level targeted to participants who never performed yoga before and was tailored to participants having LBP. This may be the reason we saw an increased adherence to the yoga intervention. The yoga classes were instructed in a group setting, which afforded participants to become familiar with each other and to the instructor of the class. The small class size and intimate and personal setting was conducive for participants to develop a sense of accountability, which increased adherence to participation. Participants were able to gain socialization and support from the group intervention providing them a positive experience to manage their LBP.

Prior yoga studies for LBP have used a variety of yoga styles. The use of hatha yoga is the most common practiced type for LBP in real-world environments, as well as therapeutic setting. ${ }^{50}$ Our study was conducted at the discretion of the yoga instructor to mimic everyday yoga classes addressing the needs of the participants. In this case the classes had a LBP treatment focus using a passive hatha yoga style initially then progressed the class to become 
more active style of yoga, with one breath associated to each movement, if the participants were responding well. The yoga teacher began the 4-week intervention with two weeks (4 sessions) of gentle hatha yoga to introduce the first-time participants to the foundations of yoga including posture, breathing, mobility, stretching, core engagement, relaxation and listening to one's body. The last two weeks (4 sessions) were more active yoga classes incorporating standing postures and sun salutations linking one breath to one movement. Currently there has been no research to suggest one type of yoga is more effective than another for providing relief of LBP. The yoga sessions involved total body activity and not isolated core muscle training. All of yoga postures performed were instructed the focus on correct posture and alignment and participants were not specifically cued to activate their core muscles during all poses. The lack of repetitive cueing to activate the TrA and LM or use of specific core muscle exercises may explain the lack of change observed in the TrA and LM muscles.

A unique aspect of this study was the use of ultrasound imaging to examine the core musculature of the TrA and LM to see if we could provide reasoning to why participants may be seeing improvements in their LBP symptoms and daily functioning. A potential limitation to the lack of change seen in the musculature or effect on outcome measures was that the classes were only 30 minutes in total. The 30-minute classes included a mindfulness and breathing warm-up for 5 minutes and resting corpse pose called savasana, used for relaxation and meditation, at the end of each session for 5 minutes allowing for approximately 20 minutes of yoga postures including instructional demonstrations. The short duration of the classes may have influenced the inactivity of the core to not show any significant changes in the timing or activation of the musculature. Ward et al. ${ }^{50}$ found large variation in frequency and duration of yoga classes from 40 to 120 minutes with the average being 75 minutes and the frequency being 1 to 6 times per 
week. Higher frequencies of classes were reported with shorter duration of $60 \mathrm{mins}$ or less. It was most common for yoga classes to be conducted one time per week in most intervention protocols. ${ }^{50}$ Duration of the yoga intervention varied from 2 weeks to 24 weeks with the most common being 12 weeks, occurring in 5 studies. ${ }^{3,42,44,45,48}$ The 1-week studies by Tekur et al. ${ }^{46}$ had daily classes of 30-60mins. The most common administration was a 12-week intervention, once per week for 75 minutes classes. This suggests that a longer duration study may be required to see benefits on core musculature and outcome measures.

Research conducted has demonstrated that individuals with LBP possess a delay in core activation of the TrA and LM that may lead to spinal instability. In the participants of this study a delayed timing of activation was not observed in the LBP group which may be explained by the age of the target population and the low grade LBP that they were experiencing. The ODI scores were $(6.02 \pm 3.83 \%)$ placing them in the minimal disability category allowing them to go about daily activities where no treatment or conservative treatment can be used. The LBP baseline scores on the ODI and VAS indicated that the symptomatic participants did not experience LBP to a severe enough level to cause large alterations in their daily activities to be reflected in their subjective measures. Utilizing a young population did not demonstrate differences either, however in future studies a more functionally disabled population would be recommended.

We may compare the results of this study to the 6-week study by Galantino et al. ${ }^{12}$ who had 22 participants undergo 60-minute hatha yoga classes twice weekly. This study was similar to our study however was two-weeks longer and focused only on hatha yoga. Galantino et al. ${ }^{12}$ found no statistical significance in their ODI $(\mathrm{p}=0.170)$ or flexibility measures $(\mathrm{p}=.534)$ between the control and intervention groups. They did find that the depression outcome (Beck 
Depression Inventory) improved significantly $(\mathrm{p}=.008)$. Their improvements in the ODI score were from $24.98 \%$ to $21.15 \%$ among the yoga group $(n=11)$ showing that their LBP group was more symptomatic then the participants in our study $(n=14)$ whose ODI scores decreased $6.0 \%$ to $5.2 \%$.

Some limitations that may have affected the results of our study could have been the small sample size of 25 participants, where only half had LBP. The youthful age of the participants in our study was the target to see if LBP could be intervened from a younger age as a prevention tool for re-occurrence. All previous literature utilized adults older than our target age range, in their mid-40's. ${ }^{12,44-46,48}$ Also, the location of the yoga classes (off campus) and the timing of the yoga class (middle of the day at 11:30am) may have limited the number of participants able to participate.

Future studies should examine flexibility measures as well as psychological outcomes regarding depression (Beck depression inventory), mood or journaling (best part of the experience, look forward to most about yoga, difficult thing to be involved with the group, impact of the instructor) to provide a more comprehensive examination of the effects of yoga. The intervention should be of longer duration and the follow-up periods should be extended to see the long term effects if LBP returned or was prevented among the affected participants. The outcome measures for future studies should examine all dimensions of health surrounding LBP addressing the mind, body and spirit that is affected by LBP. 


\section{CHAPTER VI: CONCLUSION}

This controlled laboratory study, despite its limitations, demonstrated promising results for a 4-week yoga intervention for individuals with LBP. It provides potential for long-term effects on core musculature to be examined alongside LBP outcomes to prevent recurrence if timing and activation can be improved. Future studies should examine all dimensions of human wellness, including mind, body and spirit. Group exercise has demonstrated success through a strong adherence when all individuals were beginners to yoga, and the classes were targeted for younger individuals with LBP. The improvements in the report of subjective pain should support more studies to examine the objective reasons for yoga effectiveness, and be included as a complimentary method to traditional exercise or physical therapy treatment. 


\section{REFERENCES}

1. Posadzki P, Ernst E. Yoga for low back pain: a systematic review of randomized clinical trials. Clin Rheumatol. 2011;30(9):1257-1262.

2. Cramer H, Lauche R, Haller H, Dobos G. A systematic review and meta-analysis of yoga for low back pain. Clin J Pain. 2013;29(5):450-460.

3. Cox H, Tilbrook H, Aplin J, et al. A randomised controlled trial of yoga for the treatment of chronic low back pain: results of a pilot study. Complement Ther Clin Pract. 2010;16(4):187-193.

4. Williams KA, Petronis J, Smith D, et al. Effect of Iyengar yoga therapy for chronic low back pain. Pain. 2005;115(1-2):107-117.

5. Stein KM, Weinberg J, Sherman KJ, Lemaster CM, Saper R. Participant Characteristics Associated with Symptomatic Improvement from Yoga for Chronic Low Back Pain. $J$ Yoga Phys Ther. 2014;4(1):151.

6. Lee M, Moon W, Kim J. Effect of yoga on pain, brain-derived neurotrophic factor, and serotonin in premenopausal women with chronic low back pain. Evid Based Complement Alternat Med. 2014;2014:203173.

7. Aboagye E, Karlsson ML, Hagberg J, Jensen I. Cost-effectiveness of early interventions for non-specific low back pain: a randomized controlled study investigating medical yoga, exercise therapy and self-care advice. J Rehabil Med. 2015;47(2):167-173.

8. França FR, Burke TN, Hanada ES, Marques AP. Segmental stabilization and muscular strengthening in chronic low back pain: a comparative study. Clinics (Sao Paulo). 2010;65(10):1013-1017.

9. Chang WD, Lin HY, Lai PT. Core strength training for patients with chronic low back pain. J Phys Ther Sci. 2015;27(3):619-622.

10. Teyhen DS, Rieger JL, Westrick RB, Miller AC, Molloy JM, Childs JD. Changes in deep abdominal muscle thickness during common trunk-strengthening exercises using ultrasound imaging. J Orthop Sports Phys Ther. 2008;38(10):596-605.

11. Williams K, Abildso C, Steinberg L, et al. Evaluation of the effectiveness and efficacy of Iyengar yoga therapy on chronic low back pain. Spine (Phila Pa 1976). 2009;34(19):2066-2076.

12. Galantino ML, Bzdewka TM, Eissler-Russo JL, et al. The impact of modified Hatha yoga on chronic low back pain: a pilot study. Altern Ther Health Med. 2004;10(2):56-59. 
13. Evans DD, Carter M, Panico R, Kimble L, Morlock JT, Spears MJ. Characteristics and predictors of short-term outcomes in individuals self-selecting yoga or physical therapy for treatment of chronic low back pain. PM R. 2010;2(11):1006-1015.

14. Hartfiel N, Burton C, Rycroft-Malone J, et al. Yoga for reducing perceived stress and back pain at work. Occup Med (Lond). 2012;62(8):606-612.

15. Ward L, Stebbings S, Cherkin D, Baxter GD. Yoga for functional ability, pain and psychosocial outcomes in musculoskeletal conditions: a systematic review and metaanalysis. Musculoskeletal Care. 2013;11(4):203-217.

16. Sherman KJ, Wellman RD, Cook AJ, Cherkin DC, Ceballos RM. Mediators of yoga and stretching for chronic low back pain. Evid Based Complement Alternat Med. 2013;2013:130818.

17. Ni M, Mooney K, Harriell K, Balachandran A, Signorile J. Core muscle function during specific yoga poses. Complement Ther Med. 2014;22(2):235-243.

18. Starkey C, Brown S, Ryan J. Examination of Orthopaedic and Athletic Injuries. Philadelphia, PA: F.A. Davis Company; 2010.

19. Magee DJ. Orthopaedic Physical Examination. In. 5 ed. St. Louis, Missouri: Sauders Elsevier Inc.; 2008.

20. Aluko A, DeSouza L, Peacock J. The effect of core stability exercises on variations in acceleration of trunk movement, pain, and disability during an episode of acute nonspecific low back pain: a pilot clinical trial. J Manipulative Physiol Ther. 2013;36(8):497-504.e491-493.

21. Kumar SP. Efficacy of segmental stabilization exercise for lumbar segmental instability in patients with mechanical low back pain: A randomized placebo controlled crossover study. N Am J Med Sci. 2011;3(10):456-461.

22. Louw QA, Morris LD, Grimmer-Somers K. The prevalence of low back pain in Africa: a systematic review. BMC Musculoskelet Disord. 2007;8:105.

23. Andersson GB. Epidemiological features of chronic low-back pain. Lancet. 1999;354(9178):581-585.

24. Hoy D, Brooks P, Blyth F, Buchbinder R. The Epidemiology of low back pain. Best Pract Res Clin Rheumatol. 2010;24(6):769-781.

25. Chuang LH, Soares MO, Tilbrook H, et al. A pragmatic multicentered randomized controlled trial of yoga for chronic low back pain: economic evaluation. Spine (Phila Pa 1976). 2012;37(18):1593-1601. 
26. Ferreira ML, Machado G, Latimer J, Maher C, Ferreira PH, Smeets RJ. Factors defining care-seeking in low back pain--a meta-analysis of population based surveys. Eur J Pain. 2010;14(7):747.e741-747.

27. Manchikanti L, Singh V, Falco FJ, Benyamin RM, Hirsch JA. Epidemiology of low back pain in adults. Neuromodulation. 2014;17 Suppl 2:3-10.

28. Airaksinen O, Brox JI, Cedraschi C, et al. Chapter 4. European guidelines for the management of chronic nonspecific low back pain. Eur Spine J. 2006;15 Suppl 2:S192300 .

29. Krismer M, van Tulder M, Project LBPGotBaJHSfE. Strategies for prevention and management of musculoskeletal conditions. Low back pain (non-specific). Best Pract Res Clin Rheumatol. 2007;21(1):77-91.

30. Balagué F, Mannion AF, Pellisé F, Cedraschi C. Non-specific low back pain. Lancet. 2012;379(9814):482-491.

31. Choi BK, Verbeek JH, Tam WW, Jiang JY. Exercises for prevention of recurrences of low-back pain. Cochrane Database Syst Rev. 2010(1):CD006555.

32. De Luigi AJ. Low back pain in the adolescent athlete. Phys Med Rehabil Clin N Am. 2014;25(4):763-788.

33. Hides JA, Richardson CA, Jull GA. Multifidus muscle recovery is not automatic after resolution of acute, first-episode low back pain. Spine (Phila Pa 1976).

1996;21(23):2763-2769.

34. Teyhen D, Koppenhaver S. Rehabilitative ultrasound imaging. J Physiother. 2011;57(3):196.

35. Shiri R, Karppinen J, Leino-Arjas P, Solovieva S, Viikari-Juntura E. The association between obesity and low back pain: a meta-analysis. Am J Epidemiol. 2010;171(2):135154.

36. Panjabi MM. The stabilizing system of the spine. Part I. Function, dysfunction, adaptation, and enhancement. J Spinal Disord. 1992;5(4):383-389; discussion 397.

37. Hodges PW, Richardson CA. Inefficient muscular stabilization of the lumbar spine associated with low back pain. A motor control evaluation of transversus abdominis. Spine (Phila Pa 1976). 1996;21(22):2640-2650.

38. Wong AY, Parent EC, Funabashi M, Stanton TR, Kawchuk GN. Do various baseline characteristics of transversus abdominis and lumbar multifidus predict clinical outcomes in nonspecific low back pain? A systematic review. Pain. 2013;154(12):2589-2602. 
39. Saper RB, Eisenberg DM, Davis RB, Culpepper L, Phillips RS. Prevalence and patterns of adult yoga use in the United States: results of a national survey. Altern Ther Health Med. 2004;10(2):44-49.

40. Büssing A, Ostermann T, Lüdtke R, Michalsen A. Effects of yoga interventions on pain and pain-associated disability: a meta-analysis. J Pain. 2012;13(1):1-9.

41. Patil NJ, Nagarathna R, Tekur P, Patil DN, Nagendra HR, Subramanya P. Designing, validation, and feasibility of integrated yoga therapy module for chronic low back pain. Int J Yoga. 2015;8(2):103-108.

42. Tilbrook HE, Cox H, Hewitt CE, et al. Yoga for chronic low back pain: a randomized trial. Ann Intern Med. 2011;155(9):569-578.

43. Hayden JA, van Tulder MW, Tomlinson G. Systematic review: strategies for using exercise therapy to improve outcomes in chronic low back pain. Ann Intern Med. 2005;142(9):776-785.

44. Sherman KJ, Cherkin DC, Erro J, Miglioretti DL, Deyo RA. Comparing yoga, exercise, and a self-care book for chronic low back pain: a randomized, controlled trial. Ann Intern Med. 2005;143(12):849-856.

45. Saper RB, Sherman KJ, Cullum-Dugan D, Davis RB, Phillips RS, Culpepper L. Yoga for chronic low back pain in a predominantly minority population: a pilot randomized controlled trial. Altern Ther Health Med. 2009;15(6):18-27.

46. Tekur P, Singphow C, Nagendra HR, Raghuram N. Effect of short-term intensive yoga program on pain, functional disability and spinal flexibility in chronic low back pain: a randomized control study. J Altern Complement Med. 2008;14(6):637-644.

47. Hill C. Is yoga an effective treatment in the management of patients with chronic low back pain compared with other care modalities - a systematic review. J Complement Integr Med. 2013;10.

48. Sherman KJ, Cherkin DC, Wellman RD, et al. A randomized trial comparing yoga, stretching, and a self-care book for chronic low back pain. Arch Intern Med. 2011;171(22):2019-2026.

49. Holtzman S, Beggs RT. Yoga for chronic low back pain: a meta-analysis of randomized controlled trials. Pain Res Manag. 2013;18(5):267-272.

50. Ward L, Stebbings S, Cherkin D, Baxter GD. Components and reporting of yoga interventions for musculoskeletal conditions: a systematic review of randomised controlled trials. Complement Ther Med. 2014;22(5):909-919. 
51. Teyhen DS, Miltenberger CE, Deiters HM, et al. The use of ultrasound imaging of the abdominal drawing-in maneuver in subjects with low back pain. J Orthop Sports Phys Ther. 2005;35(6):346-355.

52. Saliba SA, Croy T, Guthrie R, Grooms D, Weltman A, Grindstaff TL. Differences in transverse abdominis activation with stable and unstable bridging exercises in individuals with low back pain. N Am J Sports Phys Ther. 2010;5(2):63-73.

53. Fairbank JC. Oswestry disability index. J Neurosurg Spine. 2014;20(2):239-241.

54. Vianin M. Psychometric properties and clinical usefulness of the Oswestry Disability Index. J Chiropr Med. 2008;7(4):161-163.

55. Price DD, McGrath PA, Rafii A, Buckingham B. The validation of visual analogue scales as ratio scale measures for chronic and experimental pain. Pain. 1983;17(1):45-56.

56. Crossley KM, Bennell KL, Cowan SM, Green S. Analysis of outcome measures for persons with patellofemoral pain: which are reliable and valid? Arch Phys Med Rehabil. 2004;85(5):815-822.

57. Boonstra AM, Schiphorst Preuper HR, Reneman MF, Posthumus JB, Stewart RE. Reliability and validity of the visual analogue scale for disability in patients with chronic musculoskeletal pain. Int J Rehabil Res. 2008;31(2):165-169.

58. Himes ME, Selkow NM, Gore MA, Hart JM, Saliba SA. Transversus abdominis activation during a side-bridge exercise progression is similar in people with recurrent low back pain and healthy controls. J Strength Cond Res. 2012;26(11):3106-3112.

59. Davidson M, Keating JL. A comparison of five low back disability questionnaires: reliability and responsiveness. Phys Ther. 2002;82(1):8-24.

60. Fairbank JC, Couper J, Davies JB, O'Brien JP. The Oswestry low back pain disability questionnaire. Physiotherapy. 1980;66(8):271-273.

61. Kidgell DJ, Stokes MA, Castricum TJ, Pearce AJ. Neurophysiological responses after short-term strength training of the biceps brachii muscle. J Strength Cond Res. 2010;24(11):3123-3132.

62. Nuzzo JL, Barry BK, Gandevia SC, Taylor JL. Acute Strength Training Increases Responses to Stimulation of Corticospinal Axons. Med Sci Sports Exerc. 2016;48(1):139150.

63. Slade SC, Patel S, Underwood M, Keating JL. What are patient beliefs and perceptions about exercise for nonspecific chronic low back pain? A systematic review of qualitative studies. Clin J Pain. 2014;30(11):995-1005. 
APPENDIX: YOGA POSTURES PERFORMED

\begin{tabular}{|l|l|}
\hline \multicolumn{1}{|c|}{ Session 1 (1/24) } & \multicolumn{1}{|c|}{ Session 2 (1/26) } \\
\hline Centering / Dirgha Pranayama & Centering/Dirgha + Ujjayi \\
Torso Circles & Torso circles \\
Q Moon Stretches & Sun Breaths \\
Seated flowing twist & Window Wipers \\
Cat/Cow & Deer Flow with hold in twists \\
Wag tail & Cat/Cow \\
Child's pose & Down dog \\
Tadasana (Pelvis Neutral) & Standing forward fold \\
1/2 Sun Salutation & Ragdoll \\
Ragdoll Hold & Tadasana \\
Ardhachandrasana flow (half moon pose) & Standing forward fold with block (Co- \\
Lay down & contraction) \\
Knees to chest & Moonflowers \\
Lazy knee-down twist & Sunflowers \\
Savasana & Wide leg forward fold \\
& Hip rocking with wide legs \\
& Supported Bridge \\
& Knees to chest \\
\hline \multicolumn{1}{|c|}{ Session 3 (1/31) } & Savasana \\
\hline Centering on back (option for reclining B B & Centering \\
angle) - connecting to earth & Torso circles \\
Pelvic rocking & Q moon stretches \\
Moving to bridge (lifting one vertebrae at & Seated twists \\
a time, slowly building to full bridge, 5-8 & Seated knees to chest \\
breath hold, 3 breaths down to release) & Cat/Cow with hands behind knees \\
Windshield wipers & Patdimothanasana (long seated forward fold) \\
Udarakarshanasana (3 mins per side) & Wide leg (compass prep) \\
(supine T twist) & Cat/Cow \\
Supine Bridge with Block to supported & Downward dog \\
shoulder shand & Chair with block \\
Knees to chest (option to rock) & Standing forward fold \\
Savasana (option to move to supported & Table \\
bridge) & Savasana \\
\hline & \\
\hline Centering & Cobra/Spinal extension tutorial \\
Sun Salutation & Centering \\
Stating series (Warrior 1 $\rightarrow$ Warrior 2 $\rightarrow$ & Sun Salutation \\
Reverse Warrier $\rightarrow$ Triangle) & Standing series (Warrior 1 (with small \\
Wide leg forward fold with hip rocking) & backbend) $\rightarrow$ warrior 2 $\rightarrow$ reverse warrior \\
Standing series on opposite side & triangle) \\
Tree & Bound angle (engagement, and folding) \\
Pigeon & Udarakarshanasana (supine T twist) \\
\hline &
\end{tabular}




\begin{tabular}{|c|c|}
\hline $\begin{array}{l}\text { Udarakarshanasana (supine T twist) } \\
\text { Savasana }\end{array}$ & $\begin{array}{l}\text { Knees to chest } \\
\text { Savasana }\end{array}$ \\
\hline Session $7(2 / 14)$ & Session $8(2 / 16)$ \\
\hline $\begin{array}{l}\text { Centering - Standing } \\
\text { Sun salutations } \\
\text { Standing Series (both sides) (Lunge } \rightarrow \\
\text { reverse side angle } \rightarrow \text { warrior } 2 \rightarrow \\
\text { triangle } \\
\text { Repeat standing series in opposite order } \\
\text { Pigeon posture breakdown (option to } \\
\text { come in from table or downward dog) } \\
\text { Downward Dog } \\
\text { Plank Kriya } \\
\text { Table } \\
\text { Bridge Flow } \\
\text { Supported Bridge } \\
\text { Supported Shoulder Stand } \\
\text { Knees to chest } \\
\text { Bent knee spinal twists (supine) } \\
\text { Happy Baby } \\
\text { Savasana }\end{array}$ & $\begin{array}{l}\text { Centering } \\
\text { Sun Salutations (5x) } \\
\text { Standing series (Lunge } \rightarrow \text { Warrior } 1 \rightarrow \\
\text { warrior } 2 \rightarrow \text { reverse warrior } \rightarrow \text { triangle) } \\
\text { Wide leg forward fold } \\
\text { Repeat standing series on opposite side } \\
\text { Tadasana } \\
\text { Standing series } 2 \text { (Lunge } \rightarrow \text { reverse side } \\
\text { angle } \rightarrow \text { bound lunge with lizard } \\
\text { modification) } \\
\text { Repeat on opposite side } \\
\text { Moon flowers } 5 \mathrm{x} \\
\text { Sunflowers } 5 \mathrm{x} \\
\text { Yoga squat flow } 5 \mathrm{x} \\
\text { Yoga squat hold for } 5 \text { breaths (option for } \\
\text { crow) } \\
\text { Tadasana } \\
\text { Downward dog } \\
\text { Eifel tower } \\
\text { R knee to R elbow } \\
\text { Float between hands } \\
\mathrm{R} \text { knee to L elbow } \\
\text { Pigeon (option for twisted pigeon) - repeat } \\
\text { on L } \\
\text { Knees to chest } \\
\text { Udarakarshanasana (Supine T-twist) } \\
\text { Savasana }\end{array}$ \\
\hline
\end{tabular}

